\title{
Structures and Conservation in Historic Building Conservation
}

\author{
Title: Structures and Conservation in Historic Author: Michael Forsyth \\ Building Conservation \\ Publisher: Blackwell, Oxford, UK \\ Publication Date: (2007) \\ ISBN: $9781405111713(192 \times 246 \times 20 \mathrm{~mm})$ \\ Details: Hardback, 248 pages \\ List Price: $£ 45.00$ \\ Best price: $£ 38.00$ at www.Amazon.co.uk \\ Value for money: Good \\ Audience: Practitioners, Students of \\ Architecture, Building Conservation \\ and Surveying, Academics and \\ Managers of Historic Properties \\ Jurisdiction: UK
}

Journal of Building Appraisal (2008) 3, 335-336. doi:10.1057/palgrave.jba.2950083

This publication takes the form of a number of academic papers written by Engineers, Specialist Practitioners, Surveyors and Academics working in the field of Building Conservation. The disciplines represented include architecture, fire safety engineering, structural engineering, surveying, recording, civil engineering and geotechnical engineering. All the papers follow a common theme of the identification, measurement and remediation of issues affecting conservation of the structure of historic buildings. The topics covered include many of the factors that lead to structural decline in historic buildings and the remedial actions currently being practiced. As the engineering backgrounds of the various authors are often quite similar there appears to be a standardisation in approach by many of the authors, and a mostly common level at which technical information is laid out. It is not however a book for the beginner and most papers require a more than elementary technical knowledge of structural and building engineering issues.

The publication is part of a series of books covering both philosophical and technical conservation methodology, as well as providing an overview of the history of how structures were built. As the second volume in this series which the reviewer has read, it too follows the stated aim of providing a snap shot of a number of individual conservation engineering-related topics; however, unlike the first volume, 'Understanding HISTORIC BUILDING Conservation', this book provides greater technical depth, and is less suitable for the non-technician. As with the first volume, there is a diversity brought by the different disciplines of the contributing authors, but it is not as wide. On the evidence of this volume and the previous one, the series does appear to be developing into a comprehensive overview of conservation practice.

To summarise, given the specialist nature of much of its content, it does offer solid value at $£ 45.00$. It does meet its stated objective of providing basic and up-to-date knowledge on its topic range, and does provide a good follow up to the first more philosophically based volume. I would recommend this to the stated target audience with 
the proviso that the reader has a reasonable technical grasp of the practices of building engineering and structural appraisal. This may make it unsuitable for those looking for a first introduction to the technical issues underpinning current conservation practice.

Simon Mclean

Programme Leader Building Surveying, Nottingham Trent University E-mail: simon.mclean@ntu.ac.uk 